\title{
In a changing climate weakening tropical easterly jet induces more violent tropical storms over the north Indian Ocean
}

\author{
V. Brahmananda Rao, ${ }^{1,2}$ Camila C. Ferreira, ${ }^{1}$ S. H. Franchito, ${ }^{1}$ and S. S. V. S. \\ Ramakrishna $^{2}$ \\ Received 19 May 2008; revised 27 June 2008; accepted 2 July 2008; published 14 August 2008.
}

[1] Tropical Easterly Jet (TEJ) of summer monsoon over the north Indian ocean is weakening in recent years. The absolute easterly shear shows a strong negative correlation (significant at $99.9 \%$ level by students' two sided t-test) with the number of severe storms suggesting that a decrease in easterly shear is favorable for the formation of more severe tropical storms. For the first time in recorded history a category 5 Hurricane formed in June 2007 together with two more severe tropical storms over the north Indian ocean. Thus if the present decreasing trend of TEJ intensity continues there is a strong likelihood of the formation of tropical cyclones of hurricane intensity even during the summer monsoon. Presently these intense systems are known to form only in the pre and post monsoon seasons, when the vertical wind shear is small. Citation: Rao, V. B., C. C. Ferreira, S. H. Franchito, and S. S. V. S. Ramakrishna (2008), In a changing climate weakening tropical easterly jet induces more violent tropical storms over the north Indian Ocean, Geophys. Res. Lett., 35, L15710, doi:10.1029/2008GL034729.

\section{Introduction}

[2] Many studies suggested [Aravequia et al., 1995; Moorthi and Arakawa, 1985; Mishra and Salvekar, 1980; Shukla, 1977, 1978] that the mechanism for the generation of the monsoon depressions over the north Indian ocean which occur during the period June through September is baroclinic instability of the zonal current which culminates into tropical easterly jet (TEJ) and the higher shear is favorable for higher growth rates and larger number of depressions. The TEJ was first discovered by Koteswaram [1958]. While in a land mark paper [Gray, 1968], it was suggested that the tropical cyclones of hurricane intensity occur over several tropical oceans including the north Indian ocean basin only when the vertical wind shear is small (around $10 \mathrm{~m} \mathrm{~s}^{-1}$ between $950-200 \mathrm{hPa}$, according to Zehr [1992]). In another study [De Maria, 1996], using observational and theoretical analysis it was shown that weaker vertical shear is favorable for the tropical cyclone development and intensification. Weaker tropospheric vertical wind shear is shown to be an important factor for the development of intense or major hurricanes in the Atlantic basin [Klotzbach and Gray, 2006]. In a recent study, Rao et al. [2004] found that the TEJ strength during the Asian

\footnotetext{
${ }^{1}$ Center for Weather Forecast and Climate Studies, Instituto Nacional de Pesquisas Espaciais, São Paulo, Brazil.

${ }^{2}$ Department of Meteorology and Oceanography, Andhra University, Visakhapatnam, India.
}

Copyright 2008 by the American Geophysical Union. 0094-8276/08/2008GL034729\$05.00 summer monsoon season shows a strong decreasing trend in recent years. It is known that tropical cyclones of hurricane intensity occur in the north Indian ocean basin only during the pre and post monsoon period. This is probably because of the small vertical shear that occurs in these seasons. While during the summer monsoon season the vertical (easterly) shear is strong and prevents the formation of cyclones of hurricane intensity. But the decrease of vertical shear associated with the decrease of TEJ strength [Rao et al., 2004] might generate conditions favorable for the development of cyclones of hurricane intensity over the north Indian ocean basin even during the summer monsoon season. For the first time in recorded history a category 5 super cyclone (> $135 \mathrm{kts})$ [World Meteorological Organization, 2007] and two more severe tropical storms (STS) (> $48 \mathrm{kts}$ ) formed in June 2007. The TEJ is a typical characteristic of the north Indian ocean summer climate. The weakening of TEJ indicates a change of climate in this region. Thus, the purpose of the present paper is to investigate the relationship between the decrease in easterly shear associated with the weakening of TEJ strength and the formation of STS in this region.

\section{Data}

[3] The data used in this study were: wind and geopotential height data for the period 1950-2007 obtained from the NCEP-NCAR (National Centers for Environmental Predictions/National Center for Atmospheric Research) reanalysis data set [Kalnay et al., 1996] and data for the cyclonic systems over the north Indian ocean for the same period obtained from the Indian Meteorological Department [1979, 1996, 2007]. The four months: June, July, August and September are taken to represent the summer monsoon season. Depressions and severe storms are defined according to the wind intensity up to 33 knots and greater than 48 knots respectively [Indian Meteorological Department, 1979]. In addition, we used the recent data of Kanamitsu et al. [2002] for the period 1979-2007. Also the sea surface temperatures (SSTs) for the north Indian ocean were obtained from http://jisao.washington.edu/data_stes/\#surface temperature_gridded_data_sets.

\section{Results}

[4] Figure 1 shows the region under study. In Figure 1 the geopotential height in meters at $200 \mathrm{hPa}$ and the thickness between the 200 and $850 \mathrm{hPa}$ levels are shown. Wind vectors at $150 \mathrm{hPa}$ are also shown. The high easterly winds of more than $30 \mathrm{~m} \mathrm{~s}^{-1}$ forming the TEJ in the low latitudes and the Tibetan high can be noted in this figure. The 


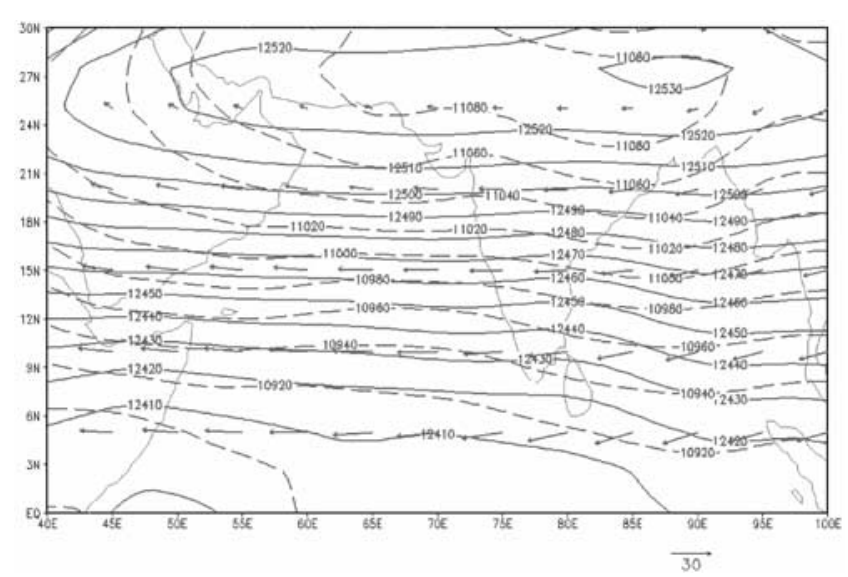

Figure 1. The region under study. Continuous lines show the $200 \mathrm{hPa}$ geopotential height in meters. Broken lines show the thickness between 200 and $850 \mathrm{hPa}$ levels. Arrows indicate the wind vectors at $150 \mathrm{hPa}$ level. All the values are means for the 4-month season: June, July, August and September, and for the period 1950 through 2007.

thickness values increase to the north indicating the increase of temperature to the north. These are some of the wellknown characteristics of the Indian summer monsoon climate [Rao, 1976].

[5] Figure 2 displays the average vertical wind shear (VWS) (zonal wind, $\mathrm{U}$ at $200 \mathrm{hPa}$ minus $\mathrm{U}$ at $850 \mathrm{hPa}$ ) for the region $0^{\circ}-5^{\circ} \mathrm{N}$ and $40^{\circ}-100^{\circ} \mathrm{E}\left(\mathrm{R}_{1}\right)$ for the period 1950-2007 and computed from the NCEP/NCAR reanalysis data [Kalnay et al., 1996]. Also shown is the VWS for the same region for the recent period 1979-2007 computed from the NCEP/DOE data [Kanamitsu et al., 2002]. The correlation coefficient $(\mathrm{cc})$ between the two variables is 0.94 significant at the $99.9 \%$ confidence level by students' two sided t-test. This demonstrates the usability of the NCEP/ NCAR reanalysis from 1950 onwards. This figure presents a clear decreasing trend of the shear. The linear trend shows a decrease of $6 \mathrm{~m} \mathrm{~s}^{-1}$ in this period, which is significant at $99.9 \%$ confidence level.

[6] Figure 3 presents VWS anomalies for the period 1950-2007. Also shown are the STS for the same period. A careful examination of the negative anomalies shows the decreasing tendency. In particular from about the year 2001 all the anomalies are positive. Thus, this figure clearly shows the weakening of the TEJ and associated decrease in easterly shear in recent years. That the weakening of the TEJ is a robust feature has been demonstrated by Sathiyamoorthy [2005] using different data sets including radiosonde data.

[7] We computed cc between the absolute VWS and the frequency of STS for the period 1950-2007. In addition to region $R_{1}$, the regions $R_{2}\left(5^{\circ} \mathrm{N}-15^{\circ} \mathrm{N}\right)$ and $\mathrm{R}_{3}\left(15^{\circ} \mathrm{N}-\right.$ $20^{\circ} \mathrm{N}$ ) for the same longitude belt as $\mathrm{R}_{1}$ are also used to calculated cc values.

[8] Table 1 shows the correlation between the absolute VWS (the average of 4-month season: June, July, August and September) over two different layers and frequency of depressions and STS for the period 1950-2007. It is seen in Table 1 that the correlation between the number of depressions and the absolute VWS is positive and highly significant, i.e. higher easterly wind shear generates more depressions. This is in agreement with the results of authors [Aravequia et al., 1995; Moorthi and Arakawa, 1985; Mishra and Salvekar, 1980; Shukla, 1977, 1978] who suggested that the baroclinic instability of the zonal current culminating into TEJ is the mechanism of generation of monsoon depressions. Interestingly, on the other hand the correlation between the absolute shear (the average of 4-month season: June, July, August and September) and the frequency of the severe storms is negative (and highly significant), i.e. lower shear is favorable for the higher number of STS. Last column of Table 1 clearly shows that over the north Indian ocean basin even during summer monsoon a lower shear is favorable for STS. To our knowledge this result is new and not noted in earlier studies. The values of cc for the recent period 1979-2007 for $R_{1}, R_{2}$ and $\mathrm{R}_{3}$ are, respectively, $-0.34,-0.53 * *$ and $-0.39 *$. Since 1979, with the advent of weather satellites both the determination of VWS and the monitoring of the tropical cyclones have improved. Thus, negative correlation noted in the last column of Table 1 strongly suggests that the decreasing trend of easterly shear favors the formation of intense cyclonic systems in future over the north Indian ocean basin even during the summer monsoon season.

[9] Severe tropical cyclonic systems of hurricane intensity are known to occur only during pre- (April and May) and post-monsoon (October and November) seasons when the vertical wind shear is within Zehr threshold value [Gray, 1968; Zehr, 1992]. Figure 4 presents the monthly variation of VWS for $R_{1}, R_{2}$ and $R_{3}$ regions and the total number of STS for the period 1950-2007. There are two maxima in STS, in May and November, the November maxima being higher. The ccs between the monthly variation of absolute VWS for the 3 regions and the number of STS are respectively $0.01,-0.42$ and $-0.69^{* *}$. This again suggests that lower VWS is favorable for the intensification of STS. With the above noted decreasing trend of wind shear, the season of tropical cyclones of hurricane intensity might extend in future to the months of June and September because of presently existing lesser wind shear in these months compared to that of July and August. Severe cyclonic storms in the recent years (one of category 5) occurred in June 2007, thus support this conclusion.

[10] Earlier, Rao et al. [2004] found a strong negative correlation between the TEJ strength (negative values of

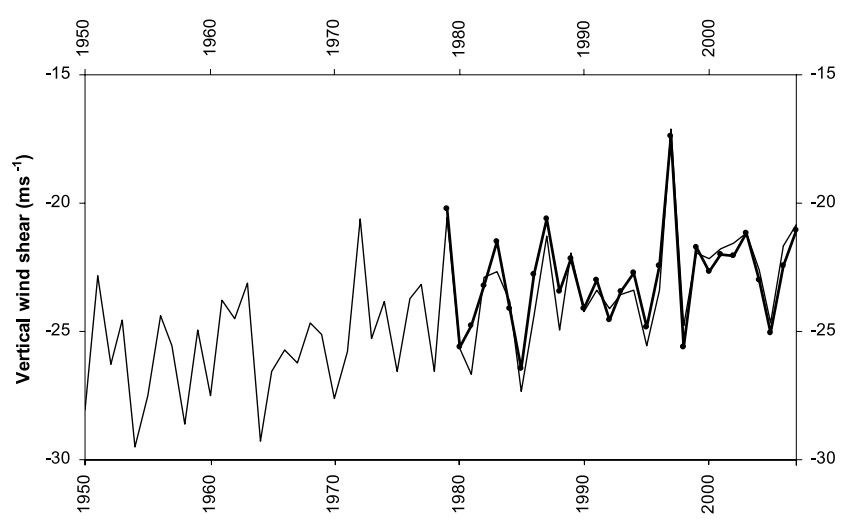

Figure 2. Variation of zonal wind difference, VWS (U200hPa-U850hPa). Thin lines show NCEP/NCAR data and thick lines show DOE data. 


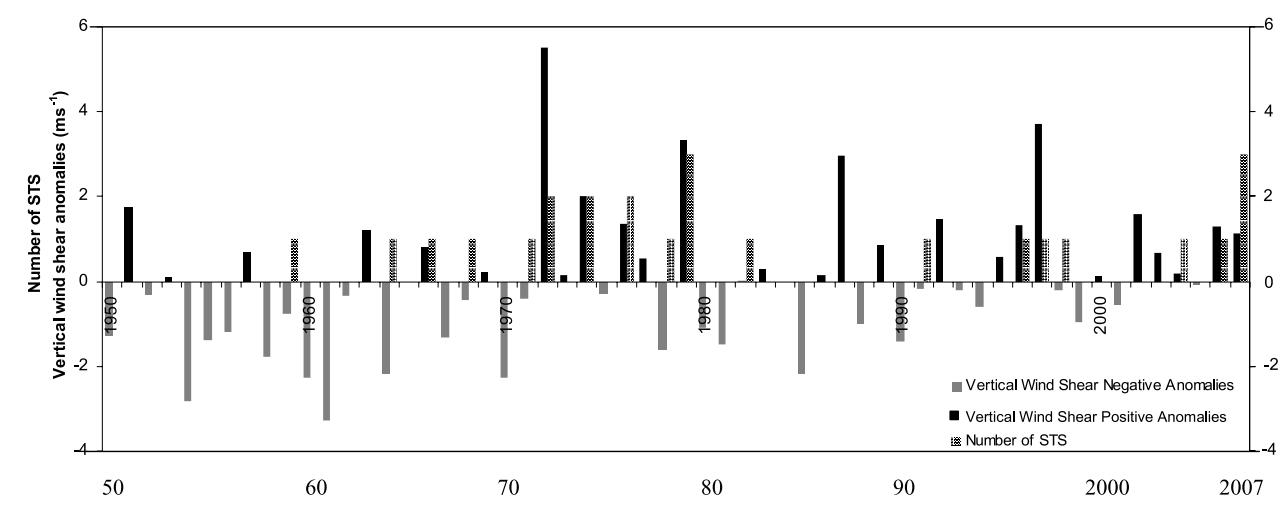

Figure 3. Anomalies of vertical wind shear. The scale of STS is the same as the shear except for the units.

zonal wind) and the number of Bay of Bengal cyclonic systems of which monsoon depressions form a major part. That is, the number of monsoon depressions tends to decrease with the decrease of TEJ strength. The positive correlation between the absolute vertical shear of TEJ and monsoon depressions in Table 1 confirms this result. The negative correlation in the last column of Table 1, as mentioned earlier, suggests that the severe tropical storms tend to increase with the decreasing easterly shear. This decrease of monsoon depressions and increase of severe storms seem to be associated with the decrease of moderate rain events and increase of extreme rain events during 1981-2000 noted by Goswami et al. [2006]. Thus the tendency to increase severe storms together with the increase of extreme rain events increases substantially the disaster potential in this region.

[11] Another parameter, which plays an important role at least in the beginning of the intensification of tropical cyclones is the SST [Gray, 1968; Emanuel, 2005]. However, several recent papers [Nyberg et al., 2007; De Maria, 1996] suggest that the VWS plays the deciding role in the subsequent intensification to the hurricane stage. In any case, it would be interesting to examine the role of SST in the development of STS and monsoon depressions. The ccs between $\mathrm{SST}$ for the Regions $\mathrm{R}_{1}, \mathrm{R}_{2}$ and $\mathrm{R}_{3}$ and the number of STS for the period 1950-2007 are respectively $0.2,0.23$ and 0.17 . None of these values is statistically significant. However, the positive correlation suggests that SST has some role to play.

Table 1. Correlation Coefficients Between the Cyclonic Systems and Vertical Wind Shear for the Regions $\mathrm{R}_{1}\left(0^{\circ}-5^{\circ} \mathrm{N}, 40^{\circ}-\right.$ $\left.100^{\circ} \mathrm{E}\right), \mathrm{R}_{2}\left(5^{\circ}-15^{\circ} \mathrm{N}, 40^{\circ}-100^{\circ} \mathrm{E}\right)$, and $\mathrm{R}_{3}\left(15^{\circ}-20^{\circ} \mathrm{N}, 40^{\circ}-\right.$ $\left.100^{\circ} \mathrm{E}\right)^{\mathrm{a}}$

\begin{tabular}{cccc}
\hline Layer & Region & Depressions & Severe Storms \\
\hline $200-850 \mathrm{hPa}$ shear & $\mathrm{R}_{1}$ & $0.29^{*}$ & $-0.34^{* *}$ \\
& $\mathrm{R}_{2}$ & $0.30^{*}$ & $-0.47^{* * *}$ \\
& $\mathrm{R}_{3}$ & 0.15 & $-0.33^{* *}$ \\
$150-850 \mathrm{hPa}$ shear & $\mathrm{R}_{1}$ & $0.39^{* *}$ & $-0.26^{*}$ \\
& $\mathrm{R}_{2}$ & $0.43^{* * *}$ & $-0.39^{* *}$ \\
& $\mathrm{R}_{3}$ & $0.33^{* *}$ & $-0.35^{* *}$ \\
\hline
\end{tabular}

${ }^{a}$ Notation: *, **, and *** indicate the levels of significance, $95 \%, 99 \%$ and $99.9 \%$ respectively, by a two sided students' t-test).
[12] To see how SST affects monsoon depressions, we computed the cc between the number of monsoon depressions during the period 1950-2007 and SST. These values for $\mathrm{R}_{1}, \mathrm{R}_{2}$ and $\mathrm{R}_{3}$ are $-0.44 * * *,-0.39 * *$ and $-0.3 *$, respectively. This shows that the higher values of SST inhibit the formation of monsoon depressions. In an earlier paper, Haltiner [1967] showed that sensible heat reduces the baroclinic instability of short and medium scale waves, such as the monsoon depressions. These results showed that the VWS and SST have opposite roles to play for the development and intensification of STS and monsoon depressions. That is, the decrease of VWS associated with weakening of TEJ is favorable for the higher number of STS and lower number of depressions. Similarly, the increase of SST is slightly favorable (because the cc between SST and the number of STS is not significant) but significantly reduces monsoon depressions. In a recent paper [Dash et al., 2007] noted that the number of weak low pressure systems (wind speed less than $8.5 \mathrm{~m} \mathrm{~s}^{-1}$ ) have increased while depressions and cyclonic storms decreased. Note that Dash et al. [2007] have included depressions and STS together. Here in the present paper we separated them. We showed that the physical mechanisms responsible for the development are different for depressions and STS, thus justifying the separation. However, since STS form a small part of the total, Dash et al. [2007] result suggests that the intensification mechanism for the development into monsoon depression stage from weak low pressure systems, namely

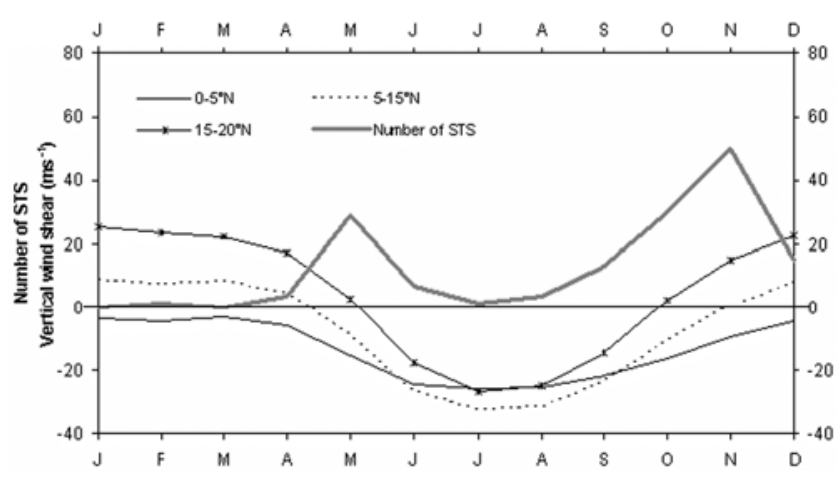

Figure 4. Annual variation of STS and the zonal wind difference. The scale of STS is the same as the shear except for the units. 
baroclinic instability, is reducing. This we showed in the present paper is due to the weakening of the TEJ. But, the relatively small number of depressions which developed from lows encounter a necessary condition, namely weak VWS, in recent years and intensified into STS. The number of STS in the recent decade 1998-2007 was 6, while in the earlier decade 1989-1998 it was only 3 ! Considering the destructive potential of these storms this increase (doubling) is disastrous for the large fraction of global population in the Indian subcontinent and adjacent regions.

\section{Conclusions}

[13] The TEJ strength during the summer monsoon period of June through September shows a strong decreasing trend in recent years. There is a strong negative correlation (significant at $99.9 \%$ confidence level) between the absolute easterly shear and the number of severe storms suggesting that a decrease in easterly shear is favorable for the formation of more severe storms. This suggests that if the present decreasing trend of TEJ intensity continues there is a strong likelihood of the formation of tropical cyclones of hurricane intensity even during the summer monsoon. At present these severe storms occur in pre and post monsoon seasons.

[14] Regarding the possible cause for the weakening of TEJ and associated decrease of easterly shear a preliminary analysis showed that the north-south temperature gradient decreased between the equator and $20^{\circ} \mathrm{N}$ for the longitude belt of $40^{\circ} \mathrm{E}-100^{\circ} \mathrm{E}$, that is the air temperature on the equator side is increasing compared to the north. These variations are particularly high above $500 \mathrm{hPa}$. In any case, further detailed analysis is needed to confirm these results.

[15] Acknowledgments. Thanks are due to S. T. Rao for stimulating scientific discussions and to Ana C. V. Ferreira for her help in preparing figures. Thanks are also due to the reviewers for useful suggestions.

\section{References}

Aravequia, J., V. B. Rao, and J. P. Bonatti (1995), The role of moist baroclinic instability in the growth and structure of monsoon depressions, J. Atmos. Sci., 52, 4393-4401.

Dash, S. K., R. K. Jenamani, S. R. Kalsi, and S. K. Panda (2007), Some evidence of climate change in twentieth-century India, Clim. Change, 85, $299-321$.

De Maria, M. (1996), Effect of vertical shear on tropical cyclone intensity change, J. Atmos. Sci., 53, 2076-2087.
Emanuel, K. E. (2005), Increasing destructiveness of tropical cyclone over the past 30 years, Nature, 436, 686-688.

Goswami, B. N., V. Venugopal, D. Sengupta, M. S. Madhusoodanan, and P. K. Xavier (2006), Increasing trend of extreme rain events over India in a warming environment, Science, 314, 1442-1445.

Gray, W. M. (1968), A global view of the origin of tropical disturbances and storms, Mon. Weather Rev., 96, 669-700.

Haltiner, G. J. (1967), The effects of sensible heat exchange on dynamics of baroclinic waves, Tellus, 19, 183-198.

India Meteorological Department (1979), Tracks of storms and depressions in the Bay of Bengal and the Arabian Sea 1877-1970, report, Gov. of India, New Delhi.

India Meteorological Department (1996), Tracks of storms and depressions in the Bay of Bengal and the Arabian Sea 1971-1990, report, Gov. of India, New Delhi.

India Meteorological Department (2007), Daily weather reports, report, Gov. of India, New Delhi.

Kalnay, E., et al. (1996), The NCEP/NCAR 40 year reanalysis project, Bull. Am. Meteorol. Soc., 77, 437-471.

Kanamitsu, M., et al. (2002), NCEP-DEO AMIP-II Reanalysis (R-2), Bull. Am. Meteorol. Soc., 83, 1631-1643.

Klotzbach, P. J., and W. M. Gray (2006), Causes of the unusually destructive 2004 Atlantic basin hurricane season, Bull. Am. Meteorol. Soc., 87, $1325-1333$

Koteswaram, P. (1958), The easterly jet stream in the tropics, Tellus, 10, $43-57$.

Mishra, S. K., and P. S. Salvekar (1980), Role of baroclinic instability in the development of monsoon depression, J. Atmos Sci., 37, 383-394.

Moorthi, S., and A. Arakawa (1985), Baroclinic instability with cumulus heating, J. Atmos. Sci., 42, 2007-2031.

Nyberg, J., et al. (2007), Low Atlantic hurricane activity in the 1970s and 1980 s compared to the past 270 years, Nature, 447, 698-701, doi:10.1038/nature05895.

Rao, B. R. S., D. V. B. Rao, and V. B. Rao (2004), Decreasing trend in the strength of Tropical Easterly Jet during the Asian summer monsoon season and the number of tropical cyclonic systems over Bay of Bengal, Geophys. Res. Lett., 31, L14103, doi:10.1029/2004GL019817.

Rao, Y. P. (1976), Southwest monsoon, Meteorol. Monogr. 1, 366 pp., India Meteorol. Dep., New Delhi.

Sathiyamoorthy, V. (2005), Large-scale reduction in the size of the tropical easterly jet, Geophys. Res. Lett., 32, L14802, doi:10.1029/2005GL022956.

Shukla, J. (1977), Barotropic-baroclinic instability of mean zonal wind during summer monsoon, Pure Appl. Geophys., 115, 1449-1462.

Shukla, J. (1978), CISK barotropic-baroclinic instability and the growth monsoon depressions, J. Atmos. Sci., 35, 495-508.

World Meteorological Organization (2007), Press release: The World Meteorological Organization reports on extreme weather and climate events, $W M O$ 791, Geneva.

Zehr, R. M. (1992) Tropical cyclogenesis in the western northern Pacific, NOAA Tech. Rep., NESDIS61, 181 pp.

C. C. Ferreira, S. H. Franchito, and V. B. Rao, Center for Weather Forecast and Climate Studies, Instituto Nacional de Pesquisas Espaciais, São Jose dos Campos, CP 515, 12245-970, SP, Brazil. (vbrao@cptec. inpe.br)

S. S. V. S. Ramakrishna, Department of Meteorology and Oceanography, Andhra University, 530003 Visakhapatnam, India. 